\title{
Improved HIV and Substance Abuse Treatment Outcomes for Released HIV-Infected Prisoners: The Impact of Buprenorphine Treatment
}

\author{
Sandra Ann Springer, Shu Chen, and Frederick L. Altice
}

\begin{abstract}
HIV-infected prisoners fare poorly after release. Though rarely available, opioid agonist therapy (OAT) may be one way to improve HIV and substance abuse treatment outcomes after release. Of the $69 \mathrm{HIV}$-infected prisoners enrolled in a randomized controlled trial of directly administered antiretroviral therapy, 48 (70\%) met DSM-IV criteria for opioid dependence. Of these, 30 (62.5\%) selected OAT, either as methadone ( $N=7,14.5 \%$ ) or buprenorphinelnaloxone (BPN/NLX; N=23, 48.0\%). Twelve-week HIV and substance abuse treatment outcomes are reported as a sub-study for those selecting BPN/NLX. Retention was high: 21 (91\%) completed BPN/NLX induction and 17 (74\%) remained on BPN/NLX after 12 weeks. Compared with baseline, the proportion with a non-detectable viral load (61\% vs $63 \% \log _{10}$ copies/ $m L)$ and mean CD4 count (367 vs 344 cells/mL) was unchanged at 12 weeks. Opiatenegative urine testing remained $83 \%$ for the 21 who completed induction. Using means from 10-point Likert scales, opioid craving was reduced from 6.0 to 1.8 within 3 days of BPN/NLX induction and satisfaction remained high at 9.5 throughout the 12 weeks. Adverse events were few and mild. BPN/NLX therapy was acceptable, safe and effective for both HIV and opioid treatment outcomes among released HIV-infected prisoners. Future randomized controlled trials are needed to affirm its benefit in this highly vulnerable population.
\end{abstract}

KEYWORDS Buprenorphine, Substance abuse, Opioid dependence, HIV, AIDS, Prisoners, Incarceration, Prevention

\section{INTRODUCTION}

In the USA, the prevalence of HIV among prisoners is approximately three times greater than in surrounding communities. ${ }^{1}$ Indeed, $14 \%$ of all people living with HIV encounter the criminal justice system annually. ${ }^{2}$ As such, prisons are an important place to detect HIV, treat it, and serve as a conduit to care after release. The availability of highly active antiretroviral therapy has transformed HIV into a chronically manageable condition, even for prisoners. ${ }^{3,4}$ Unfortunately for prisoners, including those with HIV, the 3-month period after release is a highly vulnerable time period, resulting in high rates of recidivism to prison, ${ }^{5}$ relapse to drug use, ${ }^{6-8}$ and overdose resulting in death. ${ }^{9}$ For those with HIV, decreased access to antiretroviral therapy, ${ }^{10}$ poor virological and immunological treatment outcomes, ${ }^{11,12}$ and high rates of HIV risk behaviors have been confirmed. ${ }^{13}$ Thus, researchers, practitioners, and policy makers have emphasized that the first 3 months

Springer, Chen, and Altice are with the Yale AIDS Program, New Haven, CT, USA.

Correspondence: Sandra Ann Springer, MD, Yale AIDS Program, 135 College Street, Suite 323, New Haven, CT 06510, USA. (E-mail: Sandra.springer@yale.edu) 
after release to the community is a crucial period for newly released prisoners. If successful reintegration is not achieved during this period, it is not likely to occur. $^{14-16}$

These findings create an urgent need to adapt and test evidence-based transitional interventions for this population. Opioid agonist therapy (OAT), including methadone and buprenorphine/naloxone (BPN/NLX) therapy, decrease heroin use, time to relapse, criminal activity and HIV risk behaviors and increase retention in treatment and are cost-effective to society. ${ }^{17,18}$ Moreover, $85-90 \%$ of inmates with histories of opioid dependence relapse to heroin use within one year after release, ${ }^{6,7}$ yet OAT is rarely available. ${ }^{19-21}$ For unclear reasons, the criminal justice system has not adopted these effective treatments, particularly for those with HIV who might benefit most. ${ }^{22}$

We therefore sought to establish acceptability, feasibility, and early HIV and substance abuse treatment outcomes after introducing BPN/NLX at the time of release from prison in HIV-infected patients receiving antiretroviral therapy. BPN/ NLX, unlike methadone that is a full opioid mu-agonist, is a partial mu-agonist and was selected for its favorable safety profile, reduced likelihood for overdose and death and few pharmacokinetic drug interactions with antiretroviral medications. ${ }^{23}$

\section{METHODS}

Recruitment All subjects were recruited from within a randomized controlled trial of directly administered antiretroviral therapy (DAART) among HIV-infected prisoners transitioning to the community within 90 days. Those who met DSM-IV criteria for opioid-dependence were assessed for interest in OAT with either methadone or BPN/ NLX. Additional eligibility criteria included: (1) returning to either New Haven or Hartford; (2) age $\geq 18$ years; (3) a negative urine pregnancy test for women and willingness to use contraception; and (4) expressing an interest in BPN/NLX treatment. As part of the ongoing parent study, subjects were randomized 2:1 to receive DAART versus self-administered therapy (SAT).

Study Procedures Within 90 days before community-release, all subjects underwent informed consent, baseline assessments and chart review. Assessments included demographic information, mental illness and chemical dependence screening using the Mini-International Neuropsychiatric Interview (M.I.N.I), ${ }^{24}$ Addiction Severity Index, ${ }^{25,26}$ and Alcohol Use Disorders Identification Test. ${ }^{27}$ Alcohol and drug use questions referred to the pre-incarceration period to establish historical diagnoses, as no subject was actively using drugs or alcohol. Subjects underwent secondary consent procedures after release to avoid any perceived or real coercion. Additional post-release activities included baseline physical exam and weekly assessment of opiate craving (10-point Likert-scale), buprenorphine satisfaction (10-point Likertscale), urine toxicology screening using the NIDA-6 (opiates, cocaine, methadone, benzodiazepines, marijuana, and methamphetamines), and separate urine tests for oxycodone and buprenorphine (Redwood Biotech, Santa Rosa, CA). Baseline and quarterly HIV-1 RNA levels (Amplicor 1.5; Roche) and CD4 lymphocyte counts (FACS; Quest) were obtained.

Buprenorphine Induction Process BPN/NLX induction was allowed up to 30 days post-release from prison; however, the day of release was targeted when possible. Due to low expected tolerance to opioids, subjects were initially administered 
$2.0 \mathrm{mg} / 0.5 \mathrm{mg}$ BPN/NLX and increased by $2 \mathrm{mg} / 0.5 \mathrm{mg}$ increments of BPN/NLX, as tolerated, to reduce the craving score to 1 , while avoiding opiate agonist side effects. BPN/NLX dose, craving for opiates, opioid withdrawal symptoms, opioid-agonist side effects, and urine drug screening were all collected daily during the induction and weekly thereafter. All subjects received weekly, standardized, and manual-based counseling per protocol ${ }^{28}$ for $45-60 \mathrm{~min}$ by a certified substance abuse treatment counselor. Study personnel linked counseling visits to collection of urine screens.

Buprenorphine Administration For those randomized to DAART, BPN/NLX was observed daily along with their antiretroviral therapy and other chronically prescribed medications. BPN/NLX dispensing, similar to the SAT group, was contingent upon attending weekly counseling sessions. For those in the SAT arm, BPN/NLX was contingent upon attending weekly counseling sessions where a voucher was provided to allow the pharmacy to release the BPN/NLX. Counselors provided a 7-day prescription voucher after providing a urine specimen and attending weekly counseling sessions. The voucher was not contingent on urine specimen results.

Follow-up Subjects were evaluated daily by the study clinician during the induction phase and at least monthly thereafter. Counselors met with subjects weekly, irrespective of study assignment, and assessed urine toxicology screening, opiate craving, BPN/NLX satisfaction, and adverse side effects. Structured interviews and phlebotomy for CD4 lymphocyte count and HIV-1 RNA level were conducted at weeks 4 and 12 .

Analytic Strategy Outcomes from the first 12 weeks are reported for the first 23 subjects recruited. The primary HIV treatment outcome was the proportion with a non-detectable HIV-1 RNA level 12 weeks after prison-release since this is the most vulnerable time period. CD4 counts are similarly reported. The primary substance abuse treatment outcome was retention in BPN/NLX treatment. Secondary drug treatment outcomes included the percentage of opioid-free urine toxicology results over 12 weeks. Missing urine results were adjudicated in the following sequential manner: (1) self-report at weekly visits; and (2) last value carried forward only if a single missing value was noted; (3) for subjects who remained in the trial, missing consecutive urine values were considered positive. Therefore, the proportion of positive urine tests was calculated as the percent positive out of the number who remained in the trial for each week and included missing value adjudication. Craving and satisfaction scores were calculated as the mean for those individuals whose results were reported weekly.

Institutional Review Boards at both Yale University and the University of Connecticut and the Research Committee at the Connecticut Department of Correction approved the study; a Certificate of Confidentiality was also obtained. The parent study is registered at www.clinicaltrials.gov (NCT00786396).

\section{RESULTS}

Figure 1 depicts the disposition of the 69 subjects enrolled in the parent study; $70 \%$ $(N=48)$ met DSM-IV criteria for opioid dependence. Of these, $14.5 \%(N=7)$ chose methadone, $37.5 \%(N=18)$ chose no form of OAT, and $48 \% \quad(N=23)$ chose to be inducted on BPN/NLX. 


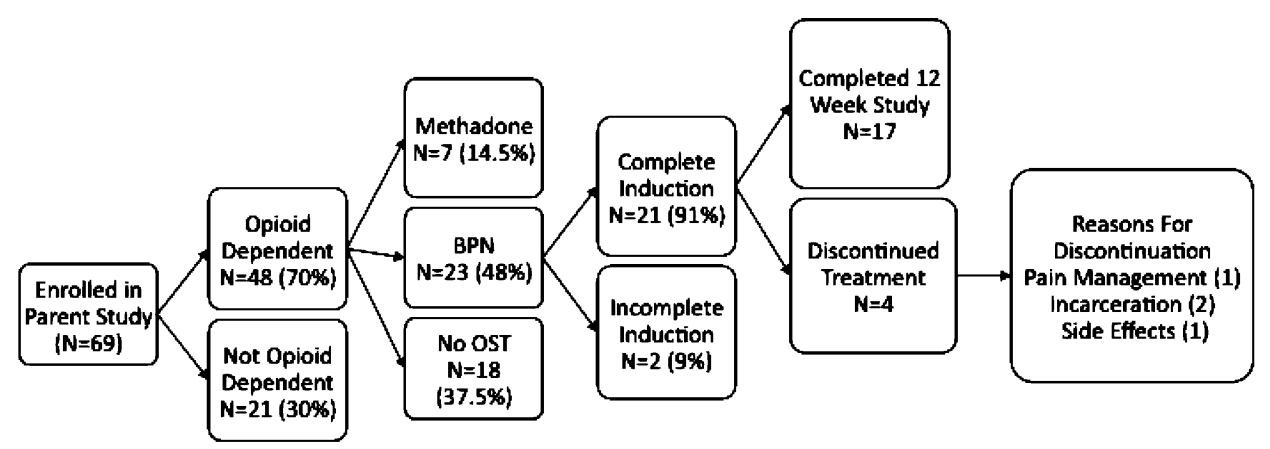

FIGURE 1. Subject allocation.

Table 1 describes the baseline characteristics for the 23 subjects choosing buprenorphine treatment. The 2:1 randomization of the parent study resulted in 16 receiving BPN/NLX as DAART and seven self-administering it. All subjects $(N=23)$ had at least one Axis I disorder: $52 \%$ had thought disorders (i.e. schizophrenia and psychosis) and $78 \%$ had mood disorders (i.e. major depression, and bipolar disorder). The majority $(61 \%$ of 23$)$ with Axis I anxiety disorders (i.e. PostTraumatic Stress Disorder, General Anxiety Disorder, Obsessive Compulsive Disorder) was also prescribed psychiatric medications.

For the primary HIV treatment outcome (see Figure 2), the proportion of subjects with a non-detectable HIV-1 RNA levels at 12 weeks did not differ from baseline ( $61 \%$ vs. $63 \%, p=0.91$ ). The mean CD4 lymphocyte count ( 367 vs. $344, p=0.89)$ did not differ statistically either. For those subjects whose HIV-1 RNA level was

TABLE 1 Baseline characteristic of study participants $(N=23)$

\begin{tabular}{lc}
\hline Characteristic & \\
\hline Mean age (years) & 46.4 \\
Gender (M/F), $N(\%)$ & $18(78): 5(22)$ \\
Race/ethnicity & \\
Black, $N(\%)$ & $9(39)$ \\
Hispanic, $N(\%)$ & $12(52)$ \\
White, $N(\%)$ & $2(9)$ \\
Co-morbid axis I mental disorders ${ }^{\mathrm{a}}$ & $23(100)$ \\
Thought disorders, N (\%) & $12(52)$ \\
Mood disorders, N (\%) & $18(78)$ \\
Anxiety disorders, N (\%) & $14(61)$ \\
Prior opioid agonist treatment & \\
Methadone, $N$ (\%) & $19(82.6)$ \\
BPN/NLX, $N$ (\%) & $5(21.7)$ \\
Methadone and BPN/NLX, $N(\%)$ & $5(21.7)$ \\
Randomization (DAART/SAT) & $16: 7$ \\
Median months of incarceration (IQ range) & $7(5-11)$ \\
Baseline AUDIT score & $6.78( \pm 7.71)$ \\
Mean baseline CD4+ lymphocytes (cells/mL) & $344( \pm 222)$ \\
HIV-1 RNA $<50$ (\%) & 63 \\
Mean HIV-1 RNA (among VL>50, copies/mL) & $4.11 \log 10$ \\
\hline
\end{tabular}

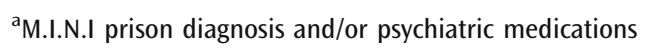




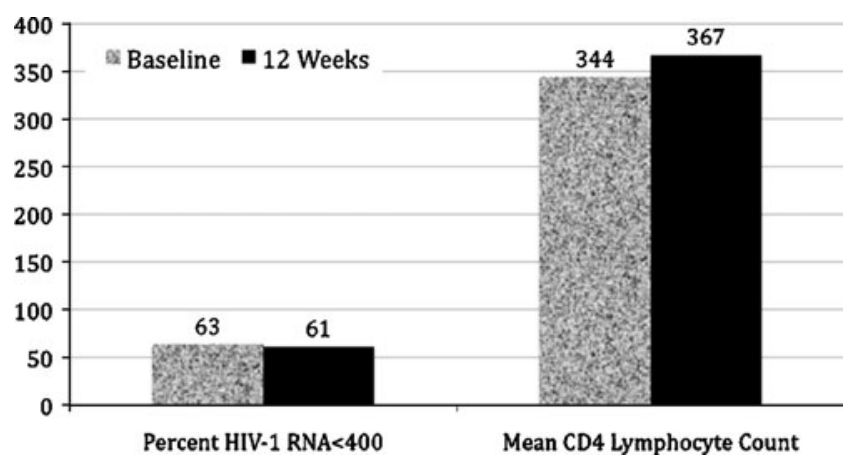

FIGURE 2. HIV treatment outcomes.

detectable, they similarly did not have a change in HIV-1 RNA levels (4.12 vs. 4.11 $\log _{10}$ copies/mL).

Among the 23 subjects initiating BPN/NLX, 91\% (N=21) completed the induction period. Two subjects left the study after a single dose of BPN/NLX and were subsequently lost to follow-up to both the BPN/NLX and the parent study. After induction, the mean daily BPN/NLX dose at which subjects were stabilized was $9.5 \mathrm{mg}$ (range, 2 to $16 \mathrm{mg}$ ). There were no differences between the mean BPN/NLX dose for those treated and not treated with atazanavir-containing regimens $(9.20 \mathrm{mg}$ vs. $8.46 \mathrm{mg} ; p=0.82$ ), yet there was a trend toward higher BPN/NLX dosage when coadministered with efavirenz-containing regimens $(10.33 \mathrm{mg}$ vs. $5.33 \mathrm{mg} ; p=0.10)$.

Compared to baseline, mean opioid craving scores decreased from 6 to 1.8 after induction completion (on average, 3 days) and remained 2.2 by the end of 12 weeks. The mean satisfaction with BPN/NLX treatment score was high at 9.5 throughout the 12-week period (see Figure 3) for the 17 retained subjects. Overall, retention was high at 12 weeks $-74 \%$ for all 23 subjects and $81 \%$ for the 21 who completed induction. One successfully inducted subject withdrew from BPN/NLX because she required a prescribed narcotic for a pain-related syndrome; two were reincarcerated

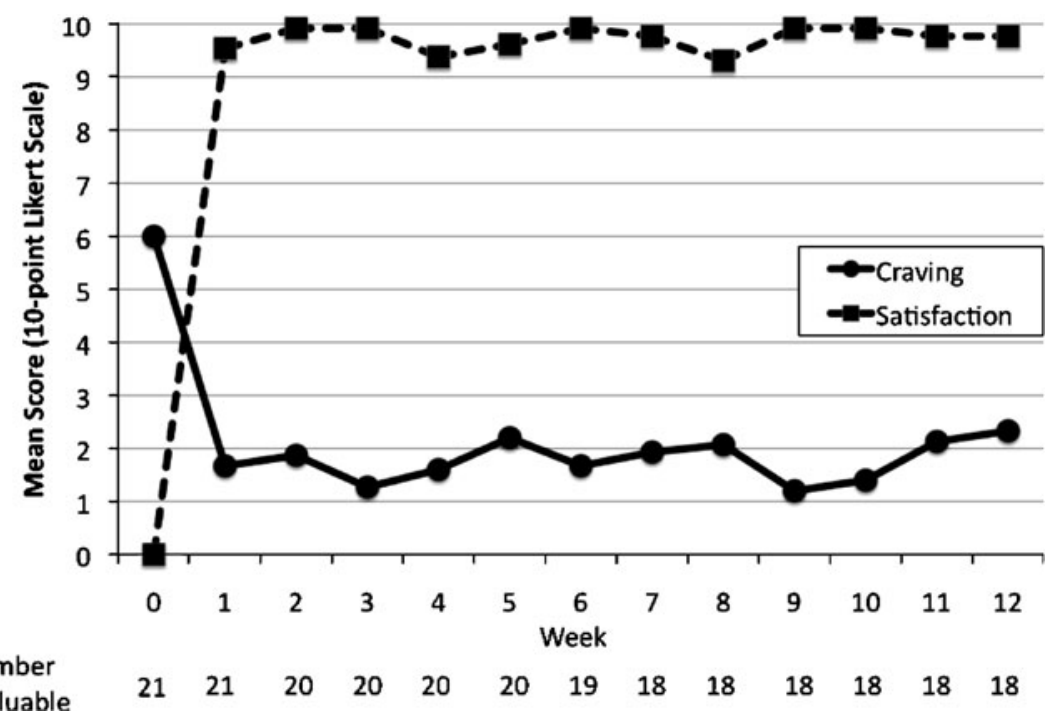

FIGURE 3. Opiate craving and satisfaction with buprenorphine treatment. 
after cocaine-relapse (opiate screens remained negative); and one withdrew due to nausea, a side effect he attributed to BPN/NLX.

Figure 4 depicts the urine toxicology results for buprenorphine, other opioids and cocaine over the 12 -week period. Urine opiate positivity decreased from $29 \%$ at baseline to $17 \%$ at the end of 12 weeks for the 17 subjects who completed 12 weeks; it was $20 \%$ for the 21 subjects who completed the 3 -day induction. Similarly urine cocaine positivity ranged from $43 \%$ at baseline to $29 \%$ at 12 weeks. Receiving HIV and BPN/NLX medications as DAART vs. SAT did not significantly differ for retention between groups $(72.2 \%$ vs $92.9 \%, p=0.17)$, but the study was underpowered to detect a difference.

The mean number of days between release from prison and receiving the first induction dose of BPN was 8.5 (range 0 to 30 days). The delay between release and starting buprenorphine resulted in positive urine testing at baseline. Comparing the 14 subjects who were inducted "early" (within the first 7 days of release), versus the nine inducted "later" (after 7 days of release), there was no statistical difference in the mean retention on treatment $(11.0$ vs. 10.6 weeks, $p=0.79)$, the proportion completing all 12 weeks $(84.6 \%$ vs. $87.5 \%, p=1.00)$, the percent of negative urine screens for opiates $(70 \%$ vs. $86 \%, p=0.47)$ and cocaine $(51.0$ vs. $70.6 \%, p=0.56)$, and the mean BPN dose at the completion of induction $(9.8$ vs. $8.9 \mathrm{mg}, p=0.31)$.

Adverse side effects, including constipation, headache, nausea and drowsiness from BPN/NLX during the 12 weeks of the study were considered mild and easily addressed by the treatment team. The one subject who withdrew from the BPN/ NLX treatment for nausea refused treatment with anti-emetics. No subject experienced opioid withdrawal symptoms or overdose during the 12-week study period. Side effects were not associated with co-administration of atazanavir or efavirenz (data not shown).

\section{DISCUSSION}

Though small, this pilot feasibility study has important implications for both clinical care and research. First, it is the first study to demonstrate that HIV treatment outcomes persist during transition from prison and there were few adverse consequences. Second,

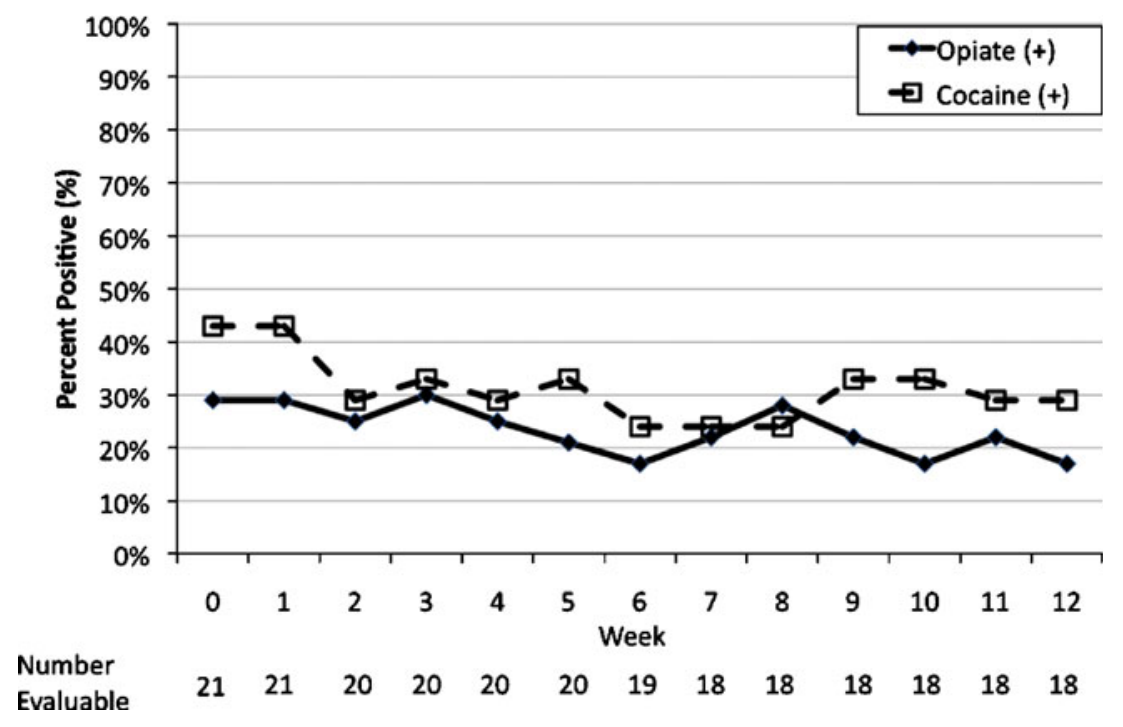

FIGURE 4. Percent of positive urine toxicology tests over time. 
it is also the first study to demonstrate the feasibility of BPN/NLX treatment as relapse prevention for opioid-dependent, HIV-infected prisoners transitioning to the community. Last, this study demonstrates not only a high preference for BPN/NLX over methadone or no OAT among those with opioid dependence, but demonstrates high levels of acceptability and satisfaction.

Prison-release studies of HIV-infected patients, including those from Connecticut, confirm poor virological and immunological outcomes within 12 weeks of release. ${ }^{11,12}$ While case management interventions have successfully linked released prisoners to care, none have confirmed stability in HIV treatment outcomes. Recent data from Texas suggest that refilling prescriptions is low among released HIVinfected prisoners, ${ }^{10}$ but this obstacle was not present in this study since all prescriptions were continued for all study subjects. The Texas study, however, did not assess the reasons for not filling prescriptions, which might have resulted from relapse to drug use. Though these pilot data are not powered sufficiently to determine if BPN/NLX treatment alone led to these successful clinical endpoints, these data remain compelling and suggest that BPN/NLX was an important factor in stabilizing the lives of subjects, resulting in improved adherence to antiretroviral therapy. Though insufficiently powered, it is now necessary to recruit larger sample sizes to determine if DAART plays a role in retention and outcomes. Ultimately, buprenorphine treatment alone without DAART needs evaluation through the rigors of a randomized controlled trial to determine its effectiveness.

Similar to most correctional settings in the Northeast where HIV prevalence rates are highest, the majority $(70 \%)$ of all released HIV-infected prisoners on antiretroviral therapy met DSM-IV criteria for opioid dependence. Not only did the majority of those with opioid dependence choose OAT over no pharmacological therapy, but also BPN/NLX was preferred over methadone. Though numerous explanations may be posited, the greater preference for BPN/NLX may reflect previous negative experiences with or perceptions about methadone among this population; ${ }^{29}$ this finding is supported by the near universal $(>80 \%)$ prior experience with methadone treatment (see Table 1). One of the misconceptions by prisoners who are no longer using illicit drugs is that "OAT would no longer be needed" after prolonged periods of forced abstinence. Absent from that perspective, however, is the recognition that opioid-relapse is high and approaches $85-90 \%{ }^{6}$ even after prolonged imprisonment.

Though the sample size was small, BPN/NLX was feasible and efficacious. There are no other studies of BPN/NLX treatment for HIV-infected released prisoners, but compared with HIV-undifferentiated released prisoners, substance abuse outcomes are similar to other studies. Among opioid-dependent prisoners in Baltimore with unknown HIV status, the use of methadone resulted in retention, efficacy and urine toxicology results similar to ours three months after release. ${ }^{6,30}$ We extended their findings to HIV-infected subjects receiving antiretroviral therapy and demonstrated sustained HIV treatment response, high retention rates $(>70 \%)$, low opiate- $(17 \%)$ and cocaine-positive $(29 \%)$ urine tests, and no associated adverse consequences between buprenorphine and HIV therapeutics. The retention rate of $74 \%(N=17 / 23)$, although potentially affected by the DAART intervention itself in this study, is higher than described in smaller studies of BPN/NLX treatment of HIVinfected persons in the USA ${ }^{31}$ and prisoners in Puerto Rico. ${ }^{32}$ This study also confirms findings reported from other small studies that have shown that BPN/NLX can be prescribed safely and effectively in HIV primary care settings; ${ }^{31,33}$ HIVundifferentiated prisoners in Puerto Rico; ${ }^{32}$ and France. ${ }^{5,34,35}$ 
Nine $(39 \%)$ of the subjects had relapsed to opioid use within a week after release from prison, accounting for the high proportion of positive urine results at baseline. To avoid early relapse and potential overdose and death, relapse prevention strategies should be initiated prior to release from prison. This is particularly true since opioid tolerance is low and risk for overdose and death is high. ${ }^{9}$ Future studies should focus on initiating treatment prior to release.

In this study of opioid dependent subjects with prolonged periods of abstinence, BPN/NLX treatment was well tolerated, but required an extended induction period over 7 days. Dosing started lower than recommended by existing guidelines for chronic opioid-using patients, ${ }^{36}$ and increases in dosage was slow and incremental. Fortunately, excess opioid-agonist effects were infrequent $(17 \%)$ during the induction period (i.e., drowsiness, nausea, headache, constipation), extinguished by the end of the induction period. Induction did, however, require longer duration of induction due to the down-regulation of opioid receptors after prolonged periods of abstinence and potentially from known symptomatic pharmacokinetic interactions with ritonavir-boosted atazanavir. ${ }^{37}$ Overall, tolerability remained high despite potential pharmacokinetic drug interactions reported between BPN/NLX and antiretroviral medications. ${ }^{23,37,38}$

Last, this study represents a population of HIV-infected individuals who often have many unmet needs and co-morbidities, and who might not otherwise receive such treatment. The unexpected universal co-occurrence of mental illness $(100 \%$ of subjects with documented Axis I disorders) suggests a particularly challenging population to treat. Indeed, collectively all subjects met criteria for triple diagnosis and their management has traditionally been fraught with multiple challenges. ${ }^{39,40}$ Left untreated, mental illness and substance use disorders contribute significantly to difficulty with maintaining appointments with medical professionals and often are associated with reincarceration. ${ }^{4,41,42}$ When effective support is offered, however, they can maintain clinical benefit from treatment. ${ }^{43}$

BPN/NLX may offer added incentives to correctional settings that might result in increased use of OAT. These include decreased: (1) regulatory procedures and licensing; (2) concerns about diversion and overdose; and (3) concerns about opioid withdrawal symptoms if a subject is not effectively and immediately linked to community services. ${ }^{22}$ One of the major barriers to BPN/NLX treatment has been the actual cost of the medication, although it has been found to be similarly costeffective as methadone. ${ }^{44}$ This concern, however, may be obviated as the BPN/NLX patent ended in late 2009 , potentially allowing for less expensive generics to emerge.

\section{CONCLUSION}

Buprenorphine induction and stabilization is a highly acceptable, tolerable and effective treatment to prevent relapse to opiate use in released HIV-infected prisoners. Importantly, it appears to be effective at maintaining HIV outcomes and potentially decreasing HIV-associated morbidity and mortality. This study initiated BPN/NLX after release from prison, but future studies, including randomized trials examining BPN/NLX induction before and after release are needed to determine the optimal timing for treatment. More importantly, better understanding of the impact that BPN/NLX treatment may have on recidivism, continuity of HIV care, ART adherence and HIV mortality through larger randomized controlled trials are urgently needed. 


\section{ACKNOWLEDGEMENTS}

The authors would like to thank Richard Schottenfeld for his thoughtful guidance and insight on providing buprenorphine to our study subjects, Paula Dellamura for her administrative assistance, and Maua Herme for her assistance with data management. Additionally, we would like to thank Mary Walton, Elizabeth Roessler, Natalie Lourenco, and Joan Marshall for their clinical oversight of the patients. Most importantly, the authors would like to thank the study participants as well as the Connecticut Department of Correction and the nurses at Correctional Managed Care at the University of Connecticut for referring subjects.

Funding. Funding for this research was provided through the National Institute on Drug Abuse for the parent study (R01 DA017059), the substudy (R21 DA019843), and for provision of career development awards (K23 DA019381, Springer and K24 DA017072, Altice). The funding source played no role in the study design or interpretation of the data.

Author Disclosure Statement. Dr. Springer directed the substudy and Dr. Altice directed the parent study. Dr. Springer and Dr. Altice contributed to the design and all writing of this manuscript. Ms. Shu performed statistical analysis of the data. All authors have approved this manuscript and there are no conflicts of interest.

OPEN ACCESS This article is distributed under the terms of the Creative Commons Attribution Noncommercial License which permits any noncommercial use, distribution, and reproduction in any medium, provided the original author(s) and source are credited.

\section{REFERENCES}

1. Spaulding AC, Seals RM, Page MJ, Brzozowski AK, Rhodes W, Hammett TM. HIV/ AIDS among inmates of and releasees from US correctional facilities, 2006: declining share of epidemic but persistent public health opportunity. PLoS ONE. 2009; 4(11): e7558.

2. Hammett TM, Harmon MP, Rhodes W. The burden of infectious disease among inmates of and releasees from US correctional facilities, 1997. Am J Public Health. 2002; 92(11): 1789-1794.

3. Centers for Disease Control (CDC). Decrease in AIDS-related mortality in a state correctional system-New York, 1995-1998. MMWR Morb Mortal Wkly Rep. 1999; 47 (51-52): 1115-1117.

4. Springer S, Friedland G, Doros G, Pesanti E, Altice FL. Antiretroviral treatment regimen outcomes among HIV-infected prisoners. New Haven: Yale AIDS Program; 2007.

5. Levasseur L, Marzo J, Ross N, Blatier C. Frequency of re-incarcerations in the same detention center: role of substitution therapy. A preliminary retrospective analysis. Ann Med Interne. 2002; 153(3 Suppl): 1S14-1S19.

6. Kinlock TW, Battjes RJ, Schwartz RP. A novel opioid maintenance program for prisoners: preliminary findings. J Subst Abuse Treat. 2002; 22(3): 141-147.

7. Nurco D, Hanlon T, Kinlock TW. Recent research on the relationship between illicit drug use and crime. Behav Sci Law. 1991; 9: 221-242.

8. Wexler HK, Lipton D, Johnson BA. A criminal justice system strategy for treating cocaine-heroin abusing offenders in custody. Washington, DC: US Department of Justice, National Institute of Justice, Office of Communication and Research Utilization; 1988. Available at: www.druglibrary.org/schaffer/GOVPUBS/cjstcha.htm. 
9. Binswanger IA, Stern MF, Deyo RA, et al. Release from prison-a high risk of death for former inmates. N Engl J Med. 2007; 356(2): 157-165.

10. Baillargeon J, Giordano TP, Rich JD, et al. Accessing antiretroviral therapy following release from prison. JAMA. 2009; 301(8): 848-857.

11. Springer SA, Pesanti E, Hodges J, Macura T, Doros G, Altice FL. Effectiveness of antiretroviral therapy among HIV-infected prisoners: reincarceration and the lack of sustained benefit after release to the community. Clin Infect Dis. 2004; 38(12): 1754-1760.

12. Stephenson BL, Wohl DA, Golin CE, Tien HC, Stewart P, Kaplan AH. Effect of release from prison and re-incarceration on the viral loads of HIV-infected individuals. Public Health Rep. 2005; 120(1): 84-88.

13. Stephenson BL, Wohl DA, McKaig R, et al. Sexual behaviours of HIV-seropositive men and women following release from prison. Int J STD AIDS. 2006; 17(2): 103-108.

14. Council of State Governments (CSG). Report of the Re-Entry Policy Council: charting the safe and successful return of prisoners to the community. New York: National Institute of Corrections, Justice Center, US Department of Justice, US Department of Labor and the US Department of Health and Human Services (DHHS); NCJ 208479; 2003.

15. Gaes G, Flanigan TP, Montiuk L, Stewart L. Adult correctional treatment. In: Tonry M, Petersilia J, eds. Prisons: crime and justice: a review of reserach, vol. 26. Chicago: University of Chicago Press; 1999: 361-425.

16. Visher C, Farrell J. Chicago communities and prisoner re-entry. Washington: The Urban Institute Justice Policy Center; 2005.

17. Amato L, Minozzi S, Davoli M, Vecchi S, Ferri MM, Mayet S. Psychosocial and pharmacological treatments versus pharmacological treatments for opioid detoxification. Cochrane Database Syst Rev. (3):CD005031, 2008.

18. World Health Organization, United Nations Office On Drugs and Crime, and the Joint United Nations Programme on HIV/AIDS. Joint position paper on substitution maintenance therapy in the management of opioid dependence and HIV/AIDS prevention. Geneva: WHO; 2004.

19. Karberg J, James D. Substance Dependence, Abuse, and Treatment of Jail Inmates, 2002. Washington, D.C. NCJ 209588, 2005.

20. Mumola C. Substance abuse and treatment, state and federal prisoners (1997). Bureau of Justice Statistics Special Report, NCJ 172871, USDepartment of Justice, Office of Justice Programs, Washington, DC. pp 1-16.

21. Chandler RK, Fletcher BW, Volkow ND. Treating drug abuse and addiction in the criminal justice system: improving public health and safety. JAMA. 2009; 301(2): 183-190.

22. Smith-Rohrberg D, Bruce RD, Altice FL. Review of corrections-based therapy for opiatedepenndent patients: Implications for buprenorphine treatment among correctional populations. J Drug Issues. 2004; 34(2): 451-480.

23. Bruce RD, Altice FL, Gourevitch MN, Friedland GH. Pharmacokinetic drug interactions between opioid agonist therapy and antiretroviral medications: implications and management for clinical practice. J Acquir Immune Defic Syndr. 2006; 41(5): 563-572.

24. Sheehan D, Lecrubier Y, Harnett-Sheehan K, et al. Reliability and validity of the MINI International Neuropsychiatric Interview (M.I.N.I.): according to the SCID-P. Eur Psychiatr. 1997; 12: 232-241.

25. McLellan AT, Kushner H, Metzger D, et al. The fifth edition of the addiction severity index. J Subst Abuse Treat. 1992; 9(3): 199-213.

26. Rosen C, Henson B, Finney J, Moos R. Consistency of self-administered and interviewbased Addiction Severity Index composite scores. Addiction. 2000; 95(3): 419-425.

27. Saunders JB, Aasland OG, Babor TF, de la Fuente JR, Grant M. Development of the Alcohol Use Disorders Identification Test (AUDIT): WHO collaborative project on early detection of persons with harmful alcohol consumption-II. Addiction. 1993; 88(6): 791-804. 
28. Copenhaver MM, Bruce RD, Altice FL. Behavioral counseling content for optimizing the use of buprenorphine for treatment of opioid dependence in community-based settings: a review of the empirical evidence. Am J Drug Alcohol Abuse. 2007; 33(5): 643-654.

29. Nurco D, Hanlon T, Shaffer J, Kinlock T, Duszynski K, Stephenson P. Differences among treatment clinic types in attitudes toward narcotic addiction. J Nerv Ment Dis. 1988; 176 (12): 71.

30. Kinlock TW, Gordon MS, Schwartz RP, O'Grady KE. A study of methadone maintenance for male prisoners: 3-month postrelease outcomes. Crim Justice Behav. 2008; 35 (1): 34-47.

31. Sullivan LE, Barry D, Moore BA, et al. A trial of integrated buprenorphine/naloxone and HIV clinical care. Clin Infect Dis. 2006; 43(Suppl 4): S184-S190.

32. Garcia C, Correa G, Hernandez-Viver A, et al. Buprenorphine-naloxone treatment for pre-release opioid-dependent inmates in Puerto Rico. J Addiction Med. 2007; 1: 126-132.

33. Sullivan LE, Bruce RD, Haltiwanger D, et al. Initial strategies for integrating buprenorphine into HIV care settings in the United States. Clin Infect Dis. 2006; 43 (Suppl 4): S191-S196.

34. Durand E. Changes in high-dose buprenorphine maintenance therapy at the FleuryMerogis (France) prison since 1996. Ann Med Interne (Paris). 2001; 152(Suppl 7): 9-14.

35. Moatti J, Carrieri M, Spire B, Gastault J, Cassuto J, Moreau J. Adherence to HAART in French HIV-infected injecting drug users: the contribution of buprenorphine drug maintenance treatment. AIDS And Behavior. 2000; 14: 151-155.

36. Center for Substance Abuse Treatment. Clinical guidelines for the use of buprenorphine in the treatment of opioid addiction. Treatment Improvement Protocol (TIP) Series 40. Rockville: Substance Abuse and Mental Health Services Administration, US Department of Health and Human Services; 2004.

37. McCance-Katz EF, Moody DE, Morse GD, et al. Interaction between buprenorphine and atazanavir or atazanavir/ritonavir. Drug Alcohol Depend. 2007; 91(2-3): 269-278.

38. McCance-Katz EF, Moody DE, Morse GD, et al. Interactions between buprenorphine and antiretrovirals. I. The nonnucleoside reverse-transcriptase inhibitors efavirenz and delavirdine. Clin Infect Dis. 2006; 43(Suppl 4): S224-S234.

39. Douaihy AB, Jou RJ, Gorske T, Salloum IM. Triple diagnosis: dual diagnosis and HIV disease, part 2. AIDS Read. 2003; 13(8): 375-382.

40. Bruce R, Altice F. Editorial comment: why treat three conditions when it is one patient? AIDS Read. 2003; 13(8): 378-379.

41. Springer S, Altice F. Improving the care for HIV-infected prisoners: an integrated prisonrelease health model. In: Greifinger R, ed. Public health behind bars: from prisons to communities. New York: Springer; 2007.

42. Springer SA, Altice FL. Managing HIV/AIDS in correctional settings. Current HIV/AIDS reports. 2005; 2(4): 165-170.

43. Zaller ND, Holmes L, Dyl AC, et al. Linkage to treatment and supportive services among HIV-positive ex-offenders in Project Bridge. J Health Care Poor Underserved. 2008; 19 (2): 522-531.

44. Connock M, Juarez-Garcia A, Jowett S, et al. Methadone and buprenorphine for the management of opioid dependence: a systematic review and economic evaluation. Health Technol Assess. 2007; 11(9): 1-171. iii-iv. 